\title{
Correlate of Socio-Economic Background and Academic Performance among Senior Secondary School Government Students Using Advance Organizer Learning Strategy
}

\author{
Dr. Adesına A.D.O \\ Mr Okewole J.O \\ Institute Of Education, Obafemi Awolowo University, Ile-Ife, Nigeria \\ email:adesinaadegbenro58@yahoo.com,delejo2002@yahoo.com
}

\section{Doi:10.5901/jesr.2014.v4n3p89}

\begin{abstract}
The studies investigated if advance organizer learning will facilitate learning of some selected Government concepts among senior secondary school students in Oyo State, Nigeria. The study assessed the differences in the academic performances from low, middle, and high socio-economic backgrounds of students after they have been exposed to advance organizers learning strategy. The design for the study was a pre- test- post-test control group design. The sample comprised 151 government students from four intact classrooms in Ibadan, Oyo State. The students were assigned to three groups namely, A, $B, C$. Each presented with a different leaning package. Group $A$ was given complete package of advance organizer plus verbal instruction, group B was taught with verbal instruction only while group $C$ was neither taught advance organiser nor given verbal instruction. Questionnaire was administered to collect data on the students' socio-economic background..Pre-test and post-test were conducted. The data collected were analysed using inferential statistics. The results of the study revealed that there was a significant difference among the three groups. This significant difference is in favour of advance organizers plus verbal instruction group. The study concluded that advance organizers learning strategy facilitated the learning of Government concepts and that students' academic performance was influenced by their socio-economic backgrounds
\end{abstract}

Keywords: Advance organizers learning strategy, socio-economic background, verbal instructions

\section{Introduction}

In the school system, good and poor academic performance of students can be tied around factors such as the socioeconomic background which includes the ability to cope with the cost and price of education, domestic and family; lack of opportunity to study; physical, environmental and development background. Other reasons include poor techniques of teaching, gender differences and lack of seriousness on the part of students.

Students have been found to perform poorly in Government as a student over the years. There have therefore been complaints on these poor performances both from government teachers and parents of the students in general. From personal interactions with students, it is the general perception that most their feel inadequate in this subject are and often complain that it is complex and difficult to understand. It cannot retain relevant knowledge in the subject area necessary for successful academic performance. This in essence gives to the question: How can government be taught in a meaningful way such that student will acquire essential knowledge for optimum use?

The question calls for among other things a study designed to investigate how the existing situation which inhibits effective teaching and learning in Government as a subject can be improve upon, that is, how poor results obtained over the years can be reserved.

On instructional strategy which has the potential to offer fertile opportunity to address the problems of teaching and learning of Government in the Advance Organiser Learning theory advocated by Ausubel (1962). It can be an appropriate instructional approach to the teaching of concepts in Government.

Ausubel (1960) explained the Advance Organiser Learning Strategy is. It is a pedagogic strategy for implementing the programme principles of progressive diffentiation and integrative reconciliation which involve the use of appropriately relevant and inclusive organise that are maximally stable and discriminable from related conceptual systems in the learners' cognitive structure. It is used to provide a conceptual framework that students can use to clarify the task ahead. It has been found in some cases to be affective in learning concepts. The studies of Ausubel and Youself (1963) and Fitzgerald and Ausubel (1963) favoured the use of Advance Organisers Learning Strategy. They all support that the 
strategy can facilitate learning in their different areas of study.

The use of Advance Organizers Learning Strategy will give room for effective investigation into the issues of gender differences, socio-economic background and academic attainment of the Government Students.

\section{Statement of Problem}

This study is designed to answer the following questions:

a) Will Government Students taught with advance organizer plus verbal instruction perform better than the group taught using verbal instruction?

b) Will there be any significant difference in the academic performance among students from low, middle and high socio-economic backgrounds after being exposed to advance organizer learning strategy?

\section{Purpose of the Study}

This study is designed to investigate the correlated of socio-economic background and academic performance of Government using Advance Organizers learning strategy. Therefore, the specific objectives of the study are to;

a) investigate if Advance Organizers learning strategy will facilitate learning of some selected Government concepts among senior secondary school students.

b) assess the differences in the academic performance of students from low, middle and high socio-economic background after exposure to Advance Organizer learning strategy.

\section{Research Hypothesis}

The study specifically tested the following hypotheses:

Ho1: There is no significant difference between the academic performance if Government students who used Advance Organizers learning Strategy plus verbal instruction and those who used verbal instructions only.

Ho2: There is no significant difference in the academic performance of students from low, middle and high socioeconomic background after being taught some selected concepts in Government using Advance Organizer Learning Strategy plus verbal instruction.

\section{Theoretical Framework}

The submission theory of Ausubel (1962) is the spring board of this study. The central idea in Ausubel theory is what he described as meaningful learning. It is a process in which new information is related to an existing relevant aspect of an individual's knowledge structure. New learning results in further changes in brain cells, but some cells, affected during meaningful learning, are the same cells that already store information similar to the new information being acquired. With continued learning of new information relevant to information already stored the nature and extent of neutral association also increase. New meaningful learning results in further growth and modifications of an existing subsume. Depending on the experience history of the individual, subsume can comparatively large and well developed, or they may be limited in the amount and variety of elements they caution. Ausubel (1962) definces subsumption as the process of linking new information to pre-existing segments in the cognitive structure. When the new ideas are related to the already existing ones in the learners' repertoire, the learner is able to discriminate and compare the ideas in a manner that remembering of the new ideas in enhanced.

According to Ausubel, Noval and Hanesian (1978) cognitive structure tends to be hierarchically organized and the process of subsumption presupposes that the subsuming ideas are directly to the learning that follows; that they are meaningful and stable, and have a common theme. If meaning derives directly from the more inclusive idea, what is subsumed is derivative; if it is a result of synthesizing and not directly related to a subsume, it is correlative. Role learning is said to occur when relevant concepts do next in the cognitive structure of an individual. New information must be learnt by rote in this wise. The emergence of new meanings in the meanings in the learner reflects the completion of a meaningful process (Ausubel, Novak and Hanesian: 1978).

According to Ausubel (1969) four types of meaningful learning were identified. The types are representational learning, in which symbols can be objects, conceptual learning, which involves understanding generalizations and relations between concepts; and discovery learning, which require rearrangement and reorganization of information. 
Meaningful learning is facilitated by prior experience. Bergan and Dun, (1975) explained meaningful learning in terms of retention. Retention is much dependent on how much related are the background ideas already in learner's cognitive structure. According to Ausubel et al. (1978), the essence of the meaningful learning process is that symbolically expressed ideas are related in a non-arbitrary and substantive (non-verbatin) fashion to what the learner already knows. It is important that, for learning to be meaningful, the materials presented for learning must also be meaningful.

Ausubel (1962) defines meaningful learning in terms of reception must also be meaningful that the content of the learning task is presented rather than discovered by the learners. Meaningful reception occurs when it involves the process of subsumption. Depending on the adequacy of prior concepts, new meaningful reception learning may be facilitated and retention of this information enhance. Ausubel (1962) Added that if the existing cognitive structure is clear, stable and suitably organised, it facilitates the learning and retention of new subject matter where as when it is unstable, ambiguous, disorganised or elastically organised, it inhibits learning and retention.

Hartley and Davies (1976) wrote that Advance organizers are meant to provide a conceptual framework that students can use to clarity the task ahead. They are process oriented. They have "a high level of abstractions, generality and inconclusiveness" (Ausubel, 1969). According to Hartley et al (1976); two types of Advance Organizer are recognizable: expository and comparative. Expository are used when the new material is not completely novel. In order to differentiate between the known and the unknown, comparative Organizers explicitly point out the ways in which the materials are both similar and different.

While meaning facilitates transfer, Ausubel identified three types of transfer: Sequential, lateral and vertical. Sequential transfer involves the transfer of a principle to new material; lateral transfer involves the transfer of one content area to another; vertical transfers occur where the transfer of one level of learning affects another at a higher level. In order to promote sequential transfer (Ausubel, 1960, 1963, 1967, 1969) "advocated the use of related level of abstraction than the learning task itself." The related ideas are when he called "advance organizaters".

Olaosun (1996) disclosed that this theory requires that learning be organised into related sequences and that both existing ideas (subsumes) and new ideas be linked in a non-arbitrary way. According to him:

Advance organizers provide general ideas which serve to anchor new ones, they present structures that are related and that serve subsuming purposes, they ensure meaningful learning as opposed to rote learning.

It should be pointed out here that Lawson and Wanska (1977), however, indicated that an advance that an advance organizer is not just an intermediary catalyst but also a 'cognitive structure' itself.

However, Ausubel and Robinson (1969) wrote that Advance Organizers can be in different forms. The visual cognitive organizer in form of maps and graphs, networks in which technical terms and concepts are charted in illustrate essential relationships and Adjunct question Organizers (Weisberg, 1970). There is the verbal form being that most commonly used in Ausubel's studies. Other forms that have been employed include photographs, thematic organizers, pre-plays and diagrams (Olaosun, 1996).

It is within the framework of Advance organizers Learning Strategy that this study intends to investigate the correlates of gender, socio-economic background and academic performance of Senior Secondary School Students. Visual cognitive organizer in form of maps, diagrams and photographs are used as advance organizer. The formats are chosen as they are very appropriate to the chosen concepts.

\section{Literature Review}

\subsection{Socio-Economic Background}

SES is a measure of an individual's family's relative economic and social ranking. A young person's SES may be constructed from a number of variables related to their family's income, parental education and occupation, or indicated by a proxy measure such as a young person's entitlement to Free School Meals (FSMs) or an indicator of deprivation in the local area. Parents are both a source of information and a major influence on students choosing courses at school. Thus, the occupational and educational status of parents could be a factor in any relationship between SES and subject choice (Sadker and Sadker 1994). In the US, mothers with no formal employment seem to encourage their children to pursue non-technical (non-science) major, which working mothers with higher occupational status seem to encourage study of technical majors (Kalmijm 1994, Kkhazzoom 1997).

Family background is influential in a number of ways, most obviously in material terms, but also terms of what is understood to be the 'natural' form of participation (Gorard and Rees 2002), Gorad et al. 2003). 'Suxxess' or 'failure' at 
school affects the choice of what to do and school affect on choice (Pustjens et al. 2004). Those who 'failed' at school often see post-school learning of all kinds as irrelevant to their needs and capacities (Selwyn et al. 2006). People develop a subjective opportunity structure that seems to filter the actual opportunities available into only those suitable for 'people like us'. Opportunities available into only those suitable for 'people like us'. Perhaps poverty, lack of role models, and a sense of 'not for us', coupled with poor experience of initial schooling can act to create a kind of lifelong attitude to learning- a negative learner identify.

Socio-economic status can be defined as a person's overall social position to which attainments in both the social and economic domain contribute. (Ainley et al, 1995: ix). When used in studies of children's school achievement, it refers to the SES of the parents or family. Socio-economic status is determined by an individual's achievement in: education; employment and occupational status; and income and wealth. Several comprehensive reviews of the relationship between SES and educational outcomes exist (Amato, 1987; Williams et al., 1991; Makherjee, 1995; Ainley et al., 1995).

\subsection{Academic Performance}

Academic performance is defined or regarded as participants' examination grades (Grade point average at the end of a particular semester or programme. It could also be seen as the level of performance in a particular field of study. Higher scores indicate better academic performance (Egbule 2004). Despite the laudable values attached to academic performance, researchers (Ugoji 2008; Egbule 2004) have shown that students' performance is declining. This could be because they are confronted with so many school and non-school related demands and responsibilities. Studies by Ayodele (1988) and Adepoju (1999) suggest how socio-psychological variables such as self-esteem, test-anxiety, locus of control, romantic relationship, work load and task could foster academic performance among students.

\subsection{The Impact of Socio-Economic Background on Academic Performance}

Socio-economic family background refers to the conditions in the family that are concerned with or related to the interaction of social and economic factors. Social factors are factors that relate to a society or its organisation; they are factors that relate to rank and status in a society (Soanes and Stevenson, 2006). Economic factors, on the other hand, are factor that are connected with the production, distribution and consumption of goods and services in a particular society or region (Black, Hashimzade and Myles, 2009).

Socio-economic family background of a student is usually determined by combining parents' educational levels, occupational status and income level (Jeynes, 2002; Tian 2006). Another major variable often used in the analysis of socio-economic family background is number of siblings in the family (Tian, 2006). Parents' educational levels could play an important role in determining a child's intellectual/academic performance (Hanafi, 2008). Parents with high level of education are most likely to engage in activities that would develop the intellectual potentials in their children and pave the way for them (the children) to perform satisfactorily in school. For example, highly educated parents are most likely to give their children the necessary academic foundations at home that will them (the children) perform well in school. Also, highly educated parents have knowledge of the necessary high quality reading materials and nutrition to provide for their children to enable them (the children) to perform well in school. The theoretical linkage between parents educational levels and students academic achievement could be found in human capital theory.

Human capital theory posits that human capital development mainly through education brings about improvement in quality of life. The theory states that formal education is highly instrumental and very essential in improving the production capacity of a person or people. According to the theory an educated person/people is a productive person/people; the theory emphasises how education increases the productivity and efficiency of workers by increasing the level of cognitive stock of economically productive human capability which a product of innate ability and investment in human beings (Olaniyan and Okemakinde, 2008). The proponents of the human capital theory consider the provision of formal education as a productive investment in human capital which is more worthwhile than investment in physical capital. The rationality behind investment in human capital, according to Babalola 2003, is based on three argument namely:

i. that new generation must be given the appropriate part of the knowledge which as already been accumulated by previous generations;

ii. that new generation should be taught how existing knowledge should be used to develop new product, to introduce new processes and production methods and social services; and

iii. that people must be encouraged to develop entirely new ideas, products, processes and methods through 
creative approaches.

Based on the human capital theory, parents educational levels are expected to highly positively correlated with students welfare and academic achievement. The higher the educational level of parents the higher will be the welfare and academic achievement of student, all other things held constant.

It is instructive to point out here that of all the variables included in the socio-economic family background of students, parents educational levels are apparently the most prominent. It is worthy of note that parents educational levels influence to the outcomes of all other variables. High level of education bring about high occupational status, high income and low birth rate; on the other hand, low level of educational goes with low occupational status, low income and high rate of procreation, all other things remaining the same. In general, occupational status is determined by level of education and income level is determined by occupational status. Also, in general, that rate or rate of procreation in a family is determined by parents educational levels and occupational status. Parents with low educational level and occupational status tend to have high rate of procreation due to ignorant about various techniques and benefits of birth control as well as not being adequately employed (that is, relative idleness), among other things.

In general, socio-economic family background affects students academic performance. Students with low socioeconomic family background often get lower test scores and are more likely to drop out of school than students with high socio-economic family background (Eamon, 2005). At this junction, it is desirable to highlight the relationship between number of sibling (as a major factor in socio-economic family background) and academic performance. Family size is highly correlated with virtually all socio-economic variable. For instance, the National Bureau of Statistic ( the apex statistical agency in Nigeria, formerly called Federal Office of Statistic) as consistently shown that household size is positively correlated with poverty (FOS, 1999; NBS, 2005). Households with the largest size on the average, have the lowest incidence of poverty. In a similar vein, family size is linked with academic achievement. Students with fewer siblings are likely to receive more parental attention and have more access to resources than students with larger number of siblings; the additional attention and support leads to better school performance (Majoribanks, 1996; Eamon, 2005; Barry, 2006).

Studies of children educational performances over time have demonstrated that social background remains one of the major sources of educational inequality. (Graetz, 1995; 28). Educational success depend very strongly on the socioeconomic status of ones parents. (Edgar, 1976, cited in Graetz 1995; 25). The effect of parental SES on children's educational outcomes may be neutralized, strengthened on mediated by a range of other contextual, family and individual characteristics. Parent may have a low income and a low status occupation, for example, but nevertheless transmit high educational aspiration to their children. What family members have (material resources of instance) can often be mediated by what family member do (for example parental support, family cohesion). The social and the economic component of socio-economic status, in other words, may have distinct and separate influence on educational outcomes. While both components are important, social factors (for instance, parents, educational attainment) have been found to be more significant than economic factors, such as a family's capacity to purchase goods and services in explaining different educational outcomes. It is argued that families where the parents are advantaged socially educationally and economically foster a higher level of achievement in their children. They also may provide higher levels of psychological support for their children through environments that encourage the development of skills necessary for success at school (Williams et al., 1980; Williams, 1987; Williams et al., 1993).

Socio-economic statue may therefore also be linked to family structure. As sole parent families on average have lower levels of income, are headed by forces, children from these families are likely to have lower educational performance (Rich, 2000).

Some other scholars have argued that the influence of family structure has been found to be only weakly associated with educational attainment, however, once controlling for other variables (Machin, 1998).

\section{Research Methodology}

The design for the study was a pre-test post-test control group design. The sample comprised 151 government students from four intact classrooms in Ibadan, Oyo State. The school was chosen based on its large population in the class used for the study and the students came from different socio-economic backgrounds. The students were assigned to three groups namely: A, B, C. Each was presented with a different learning package. Group A was given the complete package of Advance Organizers plus verbal instruction which Group B was given verbal instructions only. Group C was neither taught with Advance Organiser nor given verbal instruction.

A test of knowledge in Government and a questionnaire were used as instrument. Data were collected and 
analysed using descriptive and inferential statistics.

\section{Data Analyses and Discussion}

The table 1 below shows the pre-test analysis of academic performance of the three groups using analysis of variance.

\begin{tabular}{|l|c|c|c|c|c|}
\hline \multicolumn{1}{|c|}{ Source of Variance } & Sum of Squares & df & Mean Square & f-Ratio & P \\
\hline Between Group & 109.75 & 2 & 54.875 & 0.02 & 2.20 \\
\hline Within Group & 299965.68 & 230 & 130.29 & & \\
\hline Total & 30075.43 & 232 & & & \\
\hline
\end{tabular}

Table 1 shows the analysis of variance of the performance of Group A, B and C on pre-test. From the analysis, $F(0.42)$ $F_{c}(0.40)<F_{t}(2.20)$. it therefore means that there is no significant difference between the academic performance of Group A, B and C in the pre-test. This indicates that the general performance of the student was low in the pre-test. This was due to the fact that students did not have in-depth knowledge of the selected Government concepts which the test was based.

Table 2 : Indicates analysis of variance showing academic performance of Group A, B and C on Post- test.

\begin{tabular}{|l|c|c|c|c|c|}
\hline \multicolumn{1}{|c|}{ Source of Variance } & Sum of Squares & Df & Mean Square & F-Ratio & P \\
\hline Between Groups & 7328.900 & 2 & 3664.45 & 222 & 0.00 \\
\hline Within Group & 37799.061 & 229 & 165.06 & 222 & 000 \\
\hline Total & 45127.961 & 231 & & & \\
\hline
\end{tabular}

From table 2 above, the obtained mean squares are 7328.900 and 37799.061 respectively yielded F-value of 22.201 which is significant of the 0.05 level. This implies that there is significant difference between the academic performance of Group A, B and C on post-test.

However, to ascertain the group that has the highest multiple comparison test was carried out using the least significant difference (LSD) formula. The results are shown in the table below;

Table 3: Shows multiple comparisons of mean scores of students academic performance on post-test.

\begin{tabular}{|l|c|c|c|c|c|c|}
\hline Research Group & $\mathrm{N}$ & $\mathrm{X}$ & $\mathrm{S} . \mathrm{D}$ & Mean df & $\mathrm{t}$ & $\mathrm{p}$ \\
\hline Verbal Instruction Group & 85 & 33.941 & 12.843 & 4.6753 & 2.05 & .023 \\
\hline Control Group & 74 & 24.77 & 12.11 & & & \\
\hline Advance Organizer + Verbal Instruction Group & 73 & 38.616 & 13.563 & -4.6753 & 2.05 & .023 \\
\hline Control Group & 74 & 24.77 & 12.11 & & & \\
\hline Advance Organizer + Verbal Instruction Group & 73 & 38.616 & -13.844 & -13.844 & 2.119 & .000 \\
\hline Verbal Instruction Group & 85 & 33.941 & 12.842 & & & \\
\hline
\end{tabular}

From table 3 above, the means value of the three groups shows a mean difference of 4.6753 between group $B$ and $C$. Between group $A$ and $C$, the mean difference was 18.846. the difference between the academic performance of students in Group A and C as well as in Group A and B. Also, there is a significant difference between Group B and C.

\subsection{Test of Hypothesis 1}

The following hypothesis was tested:

H01: There is no significant difference between the academic performance of Government students who used advance organizers plus verbal instruction and those who received verbal instruction only in the learning of selected concepts.

To test this hypothesis, t-test analysis was carried out on the achievement scores of the advance organizer plus verbal instruction group and the verbal instruction only group. The result is shown in the table below. Before them table ${ }^{\star \star \star \star *}$ shows the t-test analysis of the performance of the group that used advance organizer plus verbal instruction and the verbal instruction only group on the pre-test. 
Table 4 : Shows t-test on academic achievement of the advance organizer plus verbal instruction group and the verbal instruction only group on the pre-test.

\begin{tabular}{|l|c|c|c|c|c|c|}
\hline Subject & N & X & SD & df & T & P \\
\hline Group A (Advance Organizer + Verbal Instruction) & 73 & 24.84 & 10.94 & 156 & 64.5 & 1.960 \\
\hline Group B (Verbal Instruction Only) & 85 & 23.71 & 11.00 & 156 & 64.5 & 1.960 \\
\hline
\end{tabular}

The table 4 indicates the mean achievement of the advance organizer plus verbal instruction group $(\mathrm{AO}+\mathrm{VI})$ to be 24.84 while that of the verbal instruction only group $(\mathrm{VI})$ was 23.71 . the comparison of their means gives $\mathrm{t}$-value at .645, $\mathrm{t}$ calculated was 1.960 . This value was found to be significant at 0.05 level of significance differs in their academic attainment in the pre-test.

Table 5 : Shows t-test on academic achievement of achievement of advance organizer plus verbal instruction group and the verbal instruction only group on post-test.

\begin{tabular}{|l|c|c|c|c|c|c|}
\hline Subject & N & X & SD & df & T & P \\
\hline Group A (Advance Organizer + Verbal Instruction) & 73 & 38.8 & 13.56 & 156 & 2.22 & 1.960 \\
\hline Group B (Verbal Instruction Only) & 85 & 33.9 & 12.84 & 156 & 2.22 & 1.960 \\
\hline
\end{tabular}

In table 5 , the mean achievement of the advance organizer plus verbal instruction group (Group A) was 38.6 while that of the verbal instruction only group (Group B) was 33.9. when the mean scores of the group`s were compared, the tstatistical value was found to be significant at 0.05 level of significant. This means that the null hypothesis is rejected. By implication, the verbal instruction group (Group A) performed significantly better than the verbal instruction only group (Group A).

Ho2: There is no significant difference between the academic performance of Government students who are exposed to advance organizer plus verbal instruction and those who are not taught at all.

\begin{tabular}{|l|c|c|c|c|c|}
\hline Subject of Variation & Sum of Square & df & Means Square & F & P \\
\hline Between Groups & 1070.85 & 2 & 535.42 & 3.079 & 2.37 \\
\hline Within Groups & 12174.41 & 70 & 173.92 & & \\
\hline
\end{tabular}

As indicated in table 6, the mean squares between groups and within groups are 1070.847 and 12174.413 respectively. These yield an F-value of 3.079 which is significant at the 0.05 level. This implies that there is significant different between the academic performances of students based on their socio-economic backgrounds.

In spite of the above results, an attempt was nevertheless made to determine a multiple comparison test using the least significance difference (LSD) formula was performed. The results are shown in table 7.

Ho3: There is no significant difference in the academic performance of students form low, middle and high socioeconomic backgrounds after being taught with selected concepts Government using advance organizer learning strategy.

The table indicates, analysis of variance showing different academic performance among students from different socio-economic background.

Table 7: Shows multiple comparisons of means scores of students Academic Performance with Socio-Economic Backgrounds

\begin{tabular}{|l|c|c|c|c|c|c|}
\hline Socio-Economic Background & $\mathbf{N}$ & $\mathbf{X}$ & S.D & Mean df & T & P \\
\hline Middle Socio-Economic Status & 32 & 34.8125 & 11.8443 & & & \\
\hline High Socio-Economic Status & 19 & 38.9474 & 12.6468 & 9.0511 & 3.6525 & .016 \\
\hline Low Socio-Economic Status & 22 & 43.8636 & 15.3477 & & & \\
\hline High Socio-Economic & 19 & 38.9474 & 12.6468 & -9.0511 & 3.6525 & .016 \\
\hline Low Socio-Economic Status & 22 & 43.8636 & 15.3477 & -4.9163 & 4.1303 & .238 \\
\hline Middle Socio Economic Status & 32 & 34.8125 & 11.8443 & & & \\
\hline
\end{tabular}

From table 7, multiple comparisons of the mean values of the three socio-economic background group show an average mean difference of 9.0511 between the middle socio-economic status group and the low socio-economic status group. 
This difference is significant at 0.05 level. This means that there is a significant difference between the academic performance of students from low socio-economic group and those from middle socio-economic class.

\subsection{Discussion}

Advance Organizer Learning Strategy has become very effective when one considers its impact on students academic performance. And this was what spurred the researchers to employ the strategy to improve the academic performance of Government Students. This became necessary in view of the failure being recorded each year in the West African Examination Results. In 2007, 15.3\% of the candidates failed Government as a subject; in 2008, 20, 37\% failed; in 2010, $13 \%$ failed; in 2011, $12.79 \%$ of the candidates failed Government.

In view of this, the researchers attempted to carry-out experiment using advance organizers learning strategy on Government students of public schools to investigate its efficacy as earlier observed by Ausubel (1960) that students are exposed to advance organizer better both on post-test and retention test.

In this study, three groups were used namely; (i) Group A-Advance Organizer plus Verbal Instruction (ii) Verbal Instruction group tagged Group B (iii) Control group- that was neither taught with advance organizer nor verbal instruction tagged Group C. This group was not taught at all.

From the results obtained it is very obvious that advance organizers learning strategy has positive significant effect on the students' academic performance over the students that were taught with verbal instruction only and those that were not taught at all. The mean squares between group and within group were 7328.900 and 37799.061 respectively. These results yield significant $F$ value of 22.201 which is significant at 0.05 level. This implies that there is significant difference in the academic performance of group A, B and C after given treatment to the experiments group. To determine the group that had superior performance, a multiple comparison test was conducted using the Least Significant Difference (LSD) formula. The results showed that the Advance Organizers learning strategy group recorded better performance than the two other groups. This result negates Lane (1988) and Olaosun (1996)'s findings that there was no significant difference between advance organizers groups and partial trestment groups. This same findings also do not corroborate the earlier findings of Barnes and Clawson (1975), Bricker (1987) were all of the opinion that advance organizers learning strategy does not significant difference on the students` performance over the control group.

The second null hypothesis was also tested and found that socio economic background of students determine to a great extent the academic performance as the data analysis revealed that there is a significant difference in the academic performance of the students based on socio-economic background. The findings are in line with Kobiowu (1994)'s position that contended that social class could have effects on educational opportunity, educational aspirations, mental ability and educational choices of working class children. Lord and Lord (1994) observed that positive school outcomes are associated with family environments that provided opportunity for personal autonomy and encourage the adolescent's role in family decision-making. Whereas less favourable outcomes are related to a parenting styled that is coercive, authoritarian and not a tuned to the adolescent needs for more decision-making opportunities. Also Afolabi (1990) declared that students from those parents with high incomes with high incomes, more education or those with special training and skill, more often, report themselves as happy, joyous, laughing, free of sorrow and satisfied with life. The outcomes of all these are that students from the high socio-economic parents have the opportunity of performing better in their studies than those.

However, Jean (1985) argued that while status that while status and income level do contribute to one`s socio class, they alone do not desire it.

The third hypothesis was also tested and found to be significant thereby rejected the null hypothesis as Advanced Organizer group performed better than those that were not taught at all with either advance organizer learning strategy or verbal instruction. This indicates that advance organizers learning strategy is more effective in the teaching of Government concepts, facts, principles, theories or generalizations.

\section{Conclusion}

Based upon the results derived from this empirical study, it conclude safely be said that Advance Organizers learning strategy could go a long way of improving the acquisition and understanding of some Government topics and concepts in Secondary schools in Nigeria if properly carried out by the Government teachers in our secondary schools. 


\section{Recommendations}

It is the view of those researchers that if the following recommendations are carried out, the rate of performance of students taking Government as a subject would appreciably improved.

- Government teachers should endeavour to adopt this strategy to teach Government as a subject.

- Teacher should seek out to adequately utilize this strategy to the optimal level.

- Feedback should be allowed so as to evaluate its success or otherwise.

- However, this strategy could be used with other suitable strategy

\section{References}

Ausubel D.P. (1969) Reading in school learning, New York, Holt; Rineheart and Winston Afolabi, K (1990) Effective Learning Processes, Ibadan, Cardinal Crest Ltd.

Ayodele, A (1988) Factors Promoting and Hindering Learning, Lagos, Evans Press Ltd.

Adepoju T. (1999) School Management, Ibadan, Educational Industries Ltd.

Amato B. (1987) Principles of Advance Organized learning Strategy in Education Journal of science 89 (2)86-99

Bricker E.J. (1989) The effect of Advance Organizer in the Teaching of Science, M.A. thesis, kean college.

Clawson, T. (1975) teaching in further education: An outline of principles and practice. (4th ed) London: Casel Education Ltd.

Denis L. Bary .D. (1976) The New social Studies; A Handbook for Teaching in Primary, Secondary Schools

Egbule J.F. (2004) Practical Guide to a Successful Project or Thesis in Writing and Defense, Owerri Whyte and Whyte Publishers.

Hartley J and Daries I. K. (1976) Pre-Instructional Strategies; The Role of Pre- test, Behavioral Objectives, Overviews and Advance Organizers Review of Educational Research, 46 (2) 239-255

Jean A. (1985) Social Class and School Knowledge Revised; A Copy to Ramsey, In Curriculum Inquiry, 15 (2), 207-212.

Kobiowu S. V. (1994) An Introductory Perspective of Social Foundation and Sociology of

Education, Ibadan; Cardinal Crest Ltd.

Lord, B. and Lord, K. (1994) Cognitive and Affective Factors in Learning; Journal of Educational Psychology, 54 (3) 73-84

Lane D.S. (1988) The Relationship of Students Interest and Advance Organizer Effectiveness; Comparative Educational Psychology 13 (1), $15-25$

Lawton, J.T. and Wanska, S.K. (1977) Advance Organizers as a Teaching Strategy; A reply to Barnes and Clawson. Review of Educational Research, 47 (1), 233-244

Olaosun, M.A. (1996) The Effect of Flow Charted Advance Organizers on the Retention and Transfer of Procedural Skills in Library Information. Retrieved by Fresh Undergraduates.

Ugoji, F.N, (2008) The impact of Counselling on the Academic Performance of Secondary School Students. Africa Journal for InterDisciplinary Studies, 8(2); 67-73 
